\title{
EL RETO CONSTITUCIONAL DE LA UNIÓN EUROPEA EN UN CONTEXTO DE CRISIS ECONÓMICA Y FINANCIERA ${ }^{1}$
}

\author{
THE CONSTITUTIONAL CHALLENGE OF THE EUROPEAN \\ UNION IN A CONTEXT OF ECONOMIC AND FINANCIAL CRISIS
}

\author{
JOSÉ MARÍA PORRAS RAMÍREZ ${ }^{2}$
}

\begin{abstract}
RESUMO: A União Européia, dadas suas dimensões continentais, está em uma posição ideal para fornecer soluções para demandas dos cidadãos que os Estados não mais têm condições de atender. Ao mesmo tempo, está posicionada para participar no influenciamento e determinação da política global. Mas, paradoxalmente, a União Européia ainda mantém algumas de suas características iniciais, que dificilmente são compatíveis com a idéia de democracia que está firmemente enraizada nas tradições constitucionais comuns dos estados membros e que são defendidas pela própria União. Dessa maneira, a União Européia encontra-se em um processo de transição apesar de ter instituições genuinamente representativas que estão ligadas à construção dessa nova realidade política. É assim que a União Européia, a despeito de seus inegáveis avanços, apresenta uma dinâmica institucional que é feita refém de tensões entre orientações intergovernamentais e supranacionais, ou, em outras palavras, tensões entre diversidade constitutiva e inclinações de unidade. Como resultado, possui elementos importantes de um déficit democrático, como demonstrado em aspectos como legitimidade, accountability, transparência e participação popular - um fato que gera um vácuo notável na relação estabelecida entre os governantes e os governados. Assim, a séria crise econômica e financeira que sofre a União Européia - embora tenha finalmente forçado a maioria dos estados membros, superando a resistência inicial de alguns deles a alcançar uma coordenação mais completa de suas políticas econômicas, dando à união monetária o suporte necessário dos mecanismos característicos de uma união econômica, financeira, fiscal e bancária - tem sido possível apenas ao custo de causar um novo déficit democrático de legitimidade da União. A razão é que a incipiente governança econômica européia foi fundada em um princípio intergovernamental de funcionamento, já que o Conselho Europeu e a Comissão receberam as competências de supervisão e controle com o intuito de demandar o adequado cumprimento dos objetivos de estabilidade propostos e previamente definidos nos tratados. Dessa forma,
\end{abstract}

Artigo recebido em 10.10.2013. Artigo aceito para publicação em 22.12.2013 mediante convite.

${ }^{1}$ Al recuerdo entrañable de Rafael Barranco Vela, compañero y amigo, espejo de sabiduría y bondad.

${ }^{2}$ Catedrático de Derecho Constitucional - Universidad de Granada (España).jmporras@ugr.es 
estamos ainda longe de alcançar o objetivo que expressa a ambição de formar uma organização federal completamente baseada na força de vontade democrática européia. Em suma, a Europa precisa de uma constituição para dar legitimidade democrática a suas instituições, determinando suas competências limitadas com a assunção da devida accountability por suas ações. Os atuais deficits da governança econômica européia são mera consequencia da ausência de uma real união política. Essa é a razão da necessidade de iniciar o processo constituinte. Ele dará ao projeto europeu a legitimidade e credibilidade que agora não existem e que são necessárias para sua transformação em uma resposta européia exemplar aos crescentes desafios de um mundo globalizado.

PALAVRAS-CHAVE: Globalização; União Européia; Déficit Democrático; Crise Econômica; Constituição Européia.

ABSTRACT: The European Union, given its continental dimensions, is in an ideal position to provide solutions to citizen demands that States are no longer able to meet, and at the same time, in a position to participate in the influencing and determination of global policy. But the European Union paradoxically still maintains some of its initial characteristics, which are hardly compatible with the idea of democracy that is firmly rooted in the common constitutional traditions of the Member States and which the European Union itself advocates. Accordingly, the European Union finds itself in a transition process despite the fact that it has genuinely representative institutions which are linked to the construction of this new political reality. It is therefore that the Union, in spite of its undoubted advances, presents an institutional dynamic which is held hostage to tensions between intergovernmental and supranational orientations, or in other words, tensions between constitutive diversity and unity inclinations. And as a result, it possess important elements of a democratic deficit, as demonstrated in aspects such as legitimacy, accountability, transparency and popular participation - a fact which generates a notable break or gap in the relationship established between the governing and the governed. So, the serious economical and financial crisis that is actually suffering the European Union, although it has finally forced most of the Member States, overcoming the initial resistance of some of them to reach a more complete coordination of their economic policies, giving to the monetary union the necessary support of the characteristic mechanisms of a economic, financial, fiscal and banking union, has only been possible at the expense to cause a new democratic deficit of legitimacy of the Union. The reason is that the incipient European economic governance has been founded in an intergovernmental principle of functioning, as the European Council and the Commission have received the supervision and control competences in order to demand the right achievement of the proposed stability objectives previously defined in the Treaties. Therefore, we are still far from reaching the goal that expresses the ambition to shape a federal organisation fully based on the European democratic willpower. In sum, Europe needs a constitution to give democratic legitimacy to its institutions, determining their limited competences with the assumption of the due accountability for its actions. The current deficits of the European economic governance are just a consequence of the absence of a real political union. That is the reason of the necessity to open a constituent process. It will give to the European project the legitimacy and the credibility that now that not exist and that is required for its transformation in an exemplar European reply to the increasing challenges of a globalized world.

KEYWORDS: Globalization; European Union; Democratic Deficit; Economic Crisis; European Constitution.

SUMÁRIO: 1. Globalização e Integração Supra-Estatal; 2. A União Europeia: Princípio Democrático e Sistema de Governo; 3. Os Efeitos Constitucionais da Crise Econômica e Financeira. 
SUMMARY: 1. Globalization and Supra-State Integration; 2. The European Union: Democratic Principle and Government System; 3 . The Constitutional Effects of the Economic and Financial Crisis.

\section{GLOBALIZACIÓN E INTEGRACIÓN SUPRAESTATAL}

La realidad contemporánea ofrece un testimonio elocuente de cómo, en un mundo globalizado, el Estado nacional se ha visto sobrepasado en múltiples ámbitos de actuación. Así, es evidente que los gobiernos se muestran, por sí solos, demasiado limitados para afrontar los problemas económicos o los referidos a la defensa y la lucha contra el crimen, la organización de las redes de tráfico y comunicación o los problemas que afectan al medio ambiente. En consecuencia, el Estado nacional, surgido de la Paz de Westfalia y de las Revoluciones norteamericana y francesa, hábitat natural de la sociedad industrial e instancia reguladora de sus conflictos, en el pasado percibido como el único marco para el desarrollo de las constituciones y las instituciones liberal-democráticas, al tiempo que instrumento cualificado para subvenir las necesidades sociales, es claro que hoy ya no puede satisfacer, en solitario, las demandas de los ciudadanos ${ }^{3}$. De ahí la conveniencia de construir formas jurídico-políticas de alcance mayor, superadoras del mismo, aptas para asumir y dar respuesta eficaz a los desafíos contemporáneos. Por eso, habida cuenta del debilitamiento que sufren, de resultas de presiones tanto internas como externas, las estructuras del Estado-nación, cabe preguntarse qué sentido tienen hoy las fronteras, cada vez más difusas y permeables, si los ordenamientos constitucionales y los sistemas económicos se tornan velozmente más interdependientes.

No obstante esta pérdida significativa de eficiencia, de capacidad para solucionar por sí mismo los problemas, lo cierto es que no es fácil sustituir al Estado nacional por un paradigma nuevo y alternativo, ampliamente aceptado, puesto que muchos de sus contenidos normativos, asociados al ordenamiento constitucional que lo conforma, parecen seguir siendo patrimonio exclusivo suyo, al no haberse incorporado a ninguna forma jurídico-política diferente. Así, es evidente que, por ahora, el modelo del Estado nacional, hoy extendido a todo el mundo, es el único que alberga a las instituciones liberal-democráticas propias de una sociedad plural y abierta. De ahí que aparezca como garante del derecho, la libertad personal, el predominio de la voluntad popular y la justicia social. Esta circunstancia explica por qué el Estado-nación, gestado por las grandes revoluciones liberales decimonónicas, siga sin encontrar un reemplazo, dotado de una dosis de legitimidad análoga. Y es que, aunque se constate el hecho de que el Estado-nación ha perdido el pleno control sobre su territorio, al tiempo que el monopolio del ejercicio del poder inherente a su soberanía, lo cierto es que sigue mostrándose, bien es verdad que cada vez

\footnotetext{
${ }^{3}$ H. SCHULZE, "Staat und Nation in der Europäische Geschichte" (1994). (Trad. Esp., Barcelona, Crítica, 1997, p. 253 y ss.)
} 
con mayor dificultad, como el único ámbito en el cual un amplio colectivo humano puede desarrollar, a través de cauces jurídicamente lícitos, los procedimientos democráticos que hacen posible su autogobierno, suscitando niveles apreciables de integración política y de cohesión social. De ahí los recelos ilustrados que suscitan los proyectos de sustitución de dicha forma jurídico-política por un paradigma nuevo e incierto, de dimensiones supraestatales, carente, aún, de una suficiente consistencia y contrastada legitimidad ${ }^{4}$.

Sin embargo, las grandes transformaciones que el proceso de globalización ha evidenciado no hacen sino poner de manifiesto su creciente obsolescencia, ya que su carácter cerrado, propio de una época pretérita en la que los pueblos europeos dotados de Estado eran percibidos como unidades culturales homogéneas $y$, en tanto que tales, autosuficientes, no ha hecho mas que convertirlo en una realidad desfasada, difícilmente sostenible. Por eso, no cabe mantener ya un concepto de nación que sea sinónimo de unidad, indivisibilidad y uniformidad, dada la exigencia de apertura del orden político, hacia arriba, a esa nueva sociedad mundial en la que discurren, cada vez más, las relaciones políticas, sociales y económicas; y, hacia abajo, esto es, al reconocimiento de una multiplicidad de componentes regionales, culturales y políticos, hasta ahora silenciados u obscurecidos.

La dificultad de dar respuesta a esta dicotomía indica que, en cierto sentido, los europeos de hoy nos encontramos ante una situación semejante a la que vivieron nuestros antepasados a principios del siglo XIX. Una vez más, unas transformaciones sociales, políticas, económicas, tecnológicas y culturales extraordinarias nos arrastran hacia una nueva forma de integración jurídico-política. Pero, a diferencia de los Estados nacionales emergentes en el siglo XIX, que contaban con el entusiasmo y el apoyo de una población altamente concienciada y movilizada ${ }^{5}$, son, hoy, sólo los gobiernos quienes avanzan en pos de esta unión, plenamente conscientes de su insuficiencia para abordar los múltiples desafíos contemporáneos a los que han de enfrentarse. No hay más que echar un vistazo a la exigua participación en las elecciones al Parlamento Europeo, comparándolas con las que se registran en las elecciones parlamentarias estatales para comprobar que los argumentos a favor de Europa hablan hoy sólo a las cabezas, mientras que las posiciones en contra parecen dirigirse, más bien, a los corazones. Son, pues, los propios europeos el principal obstáculo para la creación de un sentimiento de identidad paneuropeo fuerte. Lo que demuestra que la memoria histórica colectiva sigue

\footnotetext{
${ }^{4}$ J. HABERMAS, "Die postnationale Konstellation" (1998). (Trad. Esp, Barcelona, Paidós, 2000, p. 83-85 y 103 y ss.), y, también, J. H. H. WEILER and M. WIND (eds.), "European Constitutionalism beyond the State", Cambridge, Cambridge University Press, 2003, passim.

${ }^{5}$ E. HOBSBAWM, "The Age of the Revolution. Europe 1789-1848" (1997). (Trad. Esp., Barcelona, Crítica, 2011, p. 138 y ss.), C. A. BAYLY, "The Birth of the Modern World, 1780-1914" (2004). (Trad. Esp, Madrid, Siglo XXI, p. 279 y ss.).
} 
estando asociada, como efecto claramente inducido, a su identidad nacional, esto es, al intenso sentimiento de pertenencia a la respectiva comunidad política "imaginada", forjada a lo largo del siglo XIX y la primera mitad del XX, mediante la fabricación cuidadosa de un pasado común, considerado excepcional y, por lo tanto, diferente, rico en experiencias compartidas, éxitos y fracasos, derrotas y victorias, transmitidas, desde entonces, de generación en generación, a través de la familia, la iglesia y la escuela ${ }^{6}$. De ahí que los europeos no se aperciban de Europa, precisamente por la interposición de sus muchas naciones componentes y el fuerte vínculo emocional, de carácter identitario, que a ellas les mantiene aún ligados ${ }^{7}$.

El problema está en que este apego mental al pasado resulta contradictorio con el formidable reto que entraña el proceso, cada vez más complejo, de acelerada unificación sistémica de una sociedad global multicultural. Tomando plena conciencia de ese nuevo contexto, hemos, pues, de rebasar las fronteras, físicas y espirituales, de los Estados nacionales, si bien manteniendo sus conquistas históricas, a fin de considerarnos miembros solidarios de una misma comunidad política y cultural, en este caso europea, la cual deberá fundarse inevitablemente en los valores y principios civilizadores comunes, propios del constitucionalismo, expresivos, en fin, del primado del Derecho, de la democracia y de los derechos humanos ${ }^{8}$. Sólo así, apelando a esta autocomprensión normativa cabrá superar los particularismos fragmentadores y trascender las esclusas políticas y mentales construidas por los viejos Estados-nación europeos, a fin de acometer, legítima y eficazmente, los desafíos de este nuevo y más complejo presente ${ }^{9}$.

\section{LA UNIÓN EUROPEA: PRINCIPIO DEMOCRÁTICO Y ESTRUCTURA DE GOBIERNO}

En cualquier caso, los pasos que se han dado hasta ahora han sido, aunque insuficientes, muy relevantes. Así, el extraordinario proceso de integración política emprendido en su seno, el cual propiamente ha dado lugar a la "creación de una unión cada vez más estrecha entre los pueblos de Europa" (Preámbulo del Tratado de la Unión Europea: TUE), que ha desembocado en la constitución de la Unión Europea (art. 1 TUE), ha transmutado, de forma

\footnotetext{
${ }^{6}$ B. ANDERSON, "Imagined Communities: Reflections on the Origin and Spread of Nationalism" (1983). (Trad. Esp., México, Fondo de Cultura Económica, 1993, p. 23 y ss.). E. J. HOBSBAWM, "Nations and Nationalism since 1780; Programme, Myth, Reality". (1990). (Trad. Esp, Barcelona, Crítica, 1991, passim.); y A. D. SMITH, "Nationalism and Modernity". (2000). (Trad. Esp., Madrid, Istmo, 2000, p. 138 y ss.).

${ }^{7}$ H. SCHULZE, "Staat und Nation in der Europäische Geschichte" (Trad. Esp., op. cit., p. 255 y ss.)

${ }^{8}$ F. BALAGUER CALLEJÓN, "Federalismo e Integraçao Supranacional. As funçôes do Direito Constitucional nos Processos de Integraçâo Supranacional no Contexto da Globalizaçao", en P. R. BARBOSA RAMOS (ed.), "Constituçao e Federalismo no Mundo Globalizado", São Luis, EDUFMA, 2011, p. 24 y ss.

9 J. HABERMAS, "Die Einbeziehung des Anderen" (1996). (Trad. Esp., Barcelona, Paidós, p. 81 y ss.), y J. RUBIO CARRACEDO, J. Ma ROSALES y M. TOSCANO MÉNDEZ, "Ciudadanía, Nacionalismo y Derechos Humanos", Madrid, Trotta, 2000, p. 47 y ss.
} 
visible, su naturaleza ${ }^{10}$. De ese modo, aun cuando la Unión, en sus inicios, era considerada, esencialmente, una asociación voluntaria de Estados, de los que recibía sus atribuciones para alcanzar los limitados objetivos comunes, de carácter económico, que se había fijado; en la actualidad, merced a la notable evolución experimentada, con la destacada expansión y alcance adquirido por sus competencias, y el carácter, en buena medida, supranacional de su funcionamiento, la misma ha trascendido al Derecho internacional, cobrando entidad propia, de carácter materialmente constitucional. Tanto es así que, aunque el Tratado de Lisboa no lo diga expresamente, a diferencia de lo que sí hacía el fallido Tratado constitucional, adoptado en Roma, quepa afirmar que la Unión Europea posee una doble legitimidad, democrática e internacional, lo que la distingue de las organizaciones internacionales al uso, asemejándose, más bien, en tanto que "Comunidad de pueblos y de Estados", a una peculiar forma jurídico-política mixta o compuesta, "a caballo entre el Derecho internacional y el Derecho constitucional", que presenta, al tiempo, tanto elementos organizativos confederales como federales ${ }^{11}$.

En este sentido, el Derecho que produce la Unión Europea, en ejercicio de las competencias que tiene expresa y tasadamente atribuidas, las cuales son fruto del apoderamiento realizado por los Estados (art. 1.1 TUE), constituye, en todo caso, un ordenamiento jurídico diferenciado y "sui generis", que se autolegitima al fundarse en unos valores y principios específicos, vinculados a la significación histórica del constitucionalismo (art. 2 TUE). En consecuencia, dicho ordenamiento resulta diferente, tanto del internacional, como del de los Estados miembros, en el que, no obstante, se integra. Ello es consecuencia del hecho de que la Unión se manifiesta hoy como la expresión de una Unión tendencialmente federativa de Estados soberanos, lo que impone la legitimación y el funcionamiento democrático de sus instituciones, orientadas, en su seno, al ejercicio del poder político o de gobierno.

Esa contemporánea conformación "constitucional" de la Unión Europea ${ }^{12}$ nos lleva a repensar, con carácter previo, una cuestión suscitada por la teoría política contemporánea, que M. Kaufmann o P. Ridola, entre otros, han planteado con especial acierto: ¿es posible la realización plena del principio democrático más allá de las estructuras del Estado-nación?; pregunta ésta que implica, a su vez, interrogarse acerca de si cabe trasladar modelos de democracia, elaborados en el curso de la evolución constitucional de los ordenamientos

\footnotetext{
${ }^{10}$ L. Ma DíEZ-PICAZO GIMÉNEZ, “La Naturaleza de la Unión Europea”, Madrid, Civitas, 2009, p. 17-50.

${ }^{11}$ A. von BOGDANDY, "The European Union as a Supranational Federation: a conceptual attempt in the light of the Treaty of Amsterdam", en Columbia Journal of European Law, $\mathrm{n}^{\circ} 6,2000$, p. 27 y ss.

${ }_{12}$ Así, señala que la Unión Europea ha devenido un suerte de "unión constitucional" ("Verfassungsverbund"), I. PERNICE, "Europäisches und Nationales Verfassungsrecht", en "Veröffentlichungen der Vereinigung der Deutschen Staatsrechtslehrer", Band 60, München, De Gruyter, 2001, p. 149-193.
} 
estatales, a un plano más amplio, esto es, a la compleja escala supraestatal o postestatal, que es, precisamente, en la que se sitúa o mueve la Unión Europea, como singular forma de organización jurídico-política ${ }^{13}$. La pregunta encuentra especial sentido al asociarse al fenómeno o proceso de la globalización, que ha supuesto el traslado forzoso de cometidos que antaño se reservaban al Estado, al ámbito que hoy ocupan las organizaciones políticas supraestatales. La desnacionalización y consiguiente internacionalización de las políticas públicas, expresión inicial de una mundialización de la economía, el comercio y las finanzas, que hoy se extiende a prácticamente todas las esferas, requiere el consiguiente establecimiento de instancias de gobierno con capacidad de acción a nivel supranacional.

En este sentido, la Unión Europea, habida cuenta de su dimensión regional $\mathrm{o}$, si se prefiere, continental, se encuentra en una posición funcional idónea para ofrecer soluciones a las demandas ciudadanas que los Estados ya no son capaces de satisfacer, a la vez que influye y participa en la determinación de una política mundial ${ }^{14}$. Este hecho, hoy unánimemente reconocido, certifica, tanto la crisis, parece que irreversible, del paradigma jurídico-político estatal, como la urgente necesidad de legitimar, en clave necesariamente democrática, el funcionamiento de unas instituciones de gobierno de la Unión, en parte tributarias, aún, de su pasado como limitada organización internacional, orientada a la persecución de objetivos parciales, de naturaleza esencialmente económica. Esta exigencia deriva del hecho de que, si bien el Estado nacional se ha convertido, de forma acelerada, como efecto o consecuencia de la globalización, en una forma jurídico-política en trance de verse superada por el curso de la Historia, ello no debe implicar la supresión del contenido normativo, trabajosamente conquistado por el mismo, asociado a la significación histórica del constitucionalismo ${ }^{15}$.

Cabe así constatar cómo la Unión Europea no se ha desprendido, de forma ciertamente contradictoria, de algunos de los rasgos que la caracterizan desde sus inicios, los cuales son difícilmente compatibles con la idea de democracia que se encuentra firmemente arraigada en las tradiciones constitucionales comunes a sus Estados miembros y que la propia Unión Europea dice, también, auspiciar. Y así ocurre, revelando, de ese modo, hallarse en un proceso de transición, a pesar de haberse dotado, a un tiempo, de unas

\footnotetext{
${ }^{13}$ M. KAUFMANN, “Europäische Integration und Demokratieprinzip”, Baden Baden, Nomos, 1997, p. 31 y ss.; y P. RIDOLA, "II Principio Democratico fra Stati Nazionali e Unione Europea", en P. RIDOLA, "Diritto Comparato e Diritto Costituzionale Europeo", Torino, Giappichelli, 2010, p. 305 y ss.

${ }^{14}$ U. BECK, "Was ist Globalisierung?" (1997). (Trad. Esp., Barcelona, Paidós, 1998, Paidós, 1998, pássim.) y, también, O. HÖFFE, "Demokratie en Zeitalter der Globalisierung", München, C. H. Beck, 1999, pássim.

${ }^{15}$ J. HABERMAS, "Die Einbeziehung des Anderen" (1996). (Trad. Esp., op. cit., p. 102 y ss.); y, también, en su obra "Die postnationale Konstelation. Politische Essays" (1998). (Trad. Esp., op. cit., p. 105 y ss.).
} 
instituciones genuinamente representativas, vinculadas a la construcción de esa nueva realidad jurídico-política, de naturaleza, siquiera sea, materialmente constitucional $^{16}$. Por tanto, la Unión, pese a los indudables avances experimentados, presenta una dinámica institucional que, rehén de la tensión entre intergubernamentalidad y supranacionalidad, diversidad constitutiva y unidad tendencial, posee elementos importantes de déficit democrático, como se demuestra en lo que toca a aspectos tan relevantes como la legitimación, el control, la transparencia o la participación popular, hecho éste que genera, al cabo, una cesura o brecha notable en la relación que se establece entre gobernantes y gobernados ${ }^{17}$.

Con todo, el desarrollo, en un marco integrado, de las instituciones europeas, tal y como se aprecia, fundamentalmente, a partir de la promulgación del Tratado de Maastricht, es la historia de un proceso constante e ininterrumpido de democratización progresiva de sus estructuras políticas; hecho éste que no afecta, sólo, a la tradicionalmente denominada "forma de gobierno", sino, también, a ámbitos como el del reparto competencial, habida cuenta de lo que supone la incorporación del principio de subsidiariedad en la construcción de una "democracia de proximidad"; el reconocimiento de los derechos y libertades; la apertura a la autonomía local y regional; o la búsqueda efectiva de la cohesión económica, social y territorial, entre otros. Se constata así un esfuerzo reiterado, aunque aún insuficiente, por reforzar la centralidad de la democracia parlamentaria en la estructura institucional de la Unión, asociada a la irradiación, cada vez más intensa y necesaria, del principio de gobierno representativo en el ordenamiento europeo ${ }^{18}$. Así, la tendencia expresada, que vincula supranacionalidad, con la consiguiente promoción y defensa de los intereses generales o comunes, y democracia representativa, que implica una mayor legitimidad, control y consiguiente exigencia de responsabilidad, no ha hecho sino aumentar ${ }^{19}$, particularmente desde que en 1979 se introdujera, de manera efectiva, la elección directa, por sufragio universal, de los miembros del Parlamento Europeo, los cuales

\footnotetext{
${ }^{16}$ A. A. CERVATI, "Elementi di Indeterminatezza e di Conflittualitá nella Forma di Governo Europea", en Anuario dell'Associazione Italiana dei Costituzionalisti. La Costituzione europea", Padova, Cedam, 1999, p. 73 y ss.

${ }^{17}$ R. DAHL, "On Democracy" (1998). (Trad. esp., Madrid, Taurus, 1999, p. 132-135). En particular, sobre el déficit democrático de la Unión, cfr., entre otros, Z. BANKOWSKY and A. SCOTT (eds.), "The European Union and its order: the legal theory of European integration", Oxford, Blackwell, 2000, en especial, p. 169 y ss.

${ }^{18}$ G. MAJONE, "Europe's Democratic Deficit: the question of standards", en European Law Journal, vol. 4, $\mathrm{n}^{\circ}$ 1, 1998, p. 5-28. También, G. MAJONE and A. MORAVCSIK, "In defence of the democratic deficit: reassessing legitimacy in the European Union", en Journal of Common Market Studies, 2002, 40 (4), p. 603-624.

19 P. HÄBERLE, "Europäische Verfassungslehre", Baden Baden, Nomos, 4. Auflage, 2006, p. 53 y ss., y E. O. ERIKSEN and J. E. FOSSUM (eds.), "Democracy in the European Union. Integration through deliberation?". New York-London, Routledge, 2000, passim. F. BALAGUER CALLEJÓN, "El Tratado de Lisboa en el diván. Una reflexión sobre estatalidad, constitucionalidad y Unión Europea", en Revista Española de Derecho Constitucional, nº 83, 2007, p. 57 y ss.
} 
habían de agruparse de acuerdo con criterios de afinidad ideológica, esto es, con independencia de cuál fuera su procedencia estatal ${ }^{20}$.

Con todo, y a pesar de estos significativos avances, orientados a la implantación de un esquema de gobierno centralizado de carácter parlamentario, las resistencias continúan siendo muy notables. De ahí la fortaleza que sigue mostrando el elemento de representación, deliberación y decisión intergubernamental, a través de las instituciones del Consejo y, sobre todo, del Consejo Europeo, impidiendo la implantación plena, en clave organizativa, del principio democrático en el sistema institucional de la Unión, con lo que ello supone, derivadamente, de freno, también, a la transparencia, la participación, el acercamiento del gobierno a los ciudadanos y el mejor control y exigencia de responsabilidad por sus actuaciones. La persistente búsqueda de la conciliación de intereses contrapuestos, tanto nacionales como sectoriales, de naturaleza esencialmente económica, explica que, en la Unión, el juego o la dialéctica mayoría-minorías se supedite, frecuentemente, al primado de los elementos consensuales y tecnocráticos que informan, en no menor medida, la configuración de su diseño institucional $\left.\right|^{21}$.

Tales resistencias obedecen a los condicionamientos que han lastrado el desarrollo histórico del proceso de integración europea, o, lo que es igual, al rechazo, constantemente manifestado por los Estados, a ceder poder a costa del mismo ${ }^{22}$. Esa actitud se ha visto, sin duda, favorecida por la debilidad del emergente "espacio público europeo" ${ }^{\prime 23}$, y por la correlativa persistencia de espacios públicos estatales fuertes que, al capitalizar y visibilizar el discurso político, a través de los más variados cauces, dificultan la consistente afirmación de aquél. $Y$, ciertamente, mientras no se creen los presupuestos reales necesarios que aseguren un auténtico "debate público europeo", capaz de captar el interés popular, de forma análoga a como ocurre en el interior de los Estados, ese objetivo seguirá constituyendo un desafío permanente y una tarea pendiente ${ }^{24}$.

Mas, como apuntara J. Habermas, el verdadero impulso a la integración social supraestatal no depende tanto de la concurrencia comprobada de un sustrato prejurídico, de un "demos aeuropeus", en sentido histórico-cultural, "relativamente homogéneo", ligado a una concepción sustancialista de la soberanía popular ${ }^{25}$, afín a los planteamientos, más bien anacrónicos, de cuño

\footnotetext{
20 "Act and Decision concerning the election of the representatives of the Assembly by direct universal suffrage" (1976) OJ L 278,1.

${ }^{21}$ L. Ma DíEZ-PICAZO GIMÉNEZ, “La Naturaleza de la Unión Europea”, op. cit., p. 93-94.

${ }^{22}$ P. RIDOLA, "La parlamentarizzazione degli assetti istituzionali dell'Unione Europea fra democracia representativa e democracia participativa", en P. RIDOLA, "Diritto comparato e Diritto costituzionale europeo", op. cit., p. 325 y ss.

${ }^{23}$ P. HÄBERLE, “Gibt es eine europäische Öffentlichkeit?", Berlin, De Gruyter, 2000, p. 1007 y ss.

${ }^{24}$ R. DAHL, "On Democracy". (Trad. esp., op. cit., p. 132-135).

${ }^{25}$ Así, entre otros, E. W. BÖCKENFÖRDE, «Staat, Nation, Europa», Frankfurt am Main, Suhrkamp, 1999, p. 89 y ss. ; y, y también, D. GRIMM, «Die Verfassung und die Politik», München, C.H. 2002, p. 215 y ss.
} 
nacionalista, del Tribunal Federal Constitucional alemán, cuando menos desde su Sentencia acerca del Tratado de Maastricht ${ }^{26}$, lamentablemente reiterados en su Sentencia sobre el Tratado de Lisboa ${ }^{27}$; sino, más bien, de la constitución de una red comunicativa, articuladora de una esfera pública de amplitud verdaderamente europea. La misma ha de ser capaz de conformar una "cultura política común", que sea expresión y soporte de las demandas plurales de una sociedad civil, compuesta por grupos de intereses, organizaciones no gubernamentales, iniciativas y movimientos ciudadanos, susceptibles de ser asumidas por partidos políticos dispuestos a mediar para convertirlas en decisiones, jurídicamente vinculantes, de las instituciones europeas $^{28}$.

En cualquier caso, en aras de la consecución de ese fin, esto es, en orden a la construcción sincera de una democracia parlamentaria a escala europea, se hace necesario, en un plano normativo, remover algunos obstáculos interpuestos. Así, urge superar la inexistencia, frecuentemente denunciada, a pesar de la bienintencionada, aunque poco decidida, previsión programática de los Tratados, tanto de una legislación electoral uniforme, que permita la realización de comicios parlamentarios verdaderamente europeos (art. 223 TFUE), como, asimismo, promover el desarrollo efectivo de partidos políticos que, dada su condición de instrumentos fundamentales para la participación política, tengan realmente, en el marco integrado de la Unión, su espacio propio de actuación, concurriendo, en tal ámbito, a la formación y manifestación de la voluntad popular (art. 10.4 TUE) ${ }^{29}$. No en vano, la necesaria fabricación de una "cultura política europea", en apoyo de la exigencia de una democratización plena y auténtica de las estructuras institucionales de la Unión, aun siendo una labor de generaciones, al conllevar un cambio profundo en las mentalidades, precisa, como factores propiciatorios, de la realización

\footnotetext{
${ }^{26}$ BVerfGE 89, 155 Acerca de la misma, vid., entre otros, J. H. H. WEILER, "Der Staat über alles? Demos, Telos and the German Maastricht Entscheidung der Bundesverfassungsgericht", en Jarhrbuch des Öffentlichen Rechts der Gegenwart, n 42, 1994, p. 54 y ss.

${ }^{27}$ BVerfGE 2 BvE 2/08. Vid., así, con carácter general, P. HÄBERLE, "Das retrospektive Lissabon Urteil als versteinernde Maastricht II Entscheidung", en Jahrbuch des Öffentlichen Rechts der Gegenwart, $n^{\circ} 58,2010$, p. 317-336. Otra visión destacada crítica, centrada en la teoría de la democracia, en E. O. ERIKSEN and J. E. FOSSUM, "Bringing European Democracy Back in. (Or how to read the German Constitutional Court's Lisbon Treaty Ruling)", en European Law Journal, vol. 17, $\mathrm{n}^{\circ}$ 2, p. 153-171.

28 J. HABERMAS, “Remarks on Dieter Grimm's `Does Europe need a Constitution?" (1995), en "Die Einbeziehung des Anderen" (1996). (Trad. Esp., Barcelona, Paidós, 1999, p. 132-135).

${ }^{29}$ Un avance significativo lo constituye, sin duda, la "Regulation (EC) No. 2004/2003 of the European Parliament and of the Council of 4th November 2003, on the regulations governing political parties at European level and the rules regarding their funding". Vid., acerca de la relevancia que han de tener los partidos políticos a escala europea T. JANSEN, "Pan-European political parties". The Federal Trust for Education \& Research, 14 European Essay, 2001, p. 15 y ss. S. MICOSSI, "Democracy in the European Union", Bruxelles, Centre for European Policy Studies, 2008, p. 7; J. B. DONNELLY and M. JOPP, "European political parties and democracy in the EU", en G. BONVICINI (ed.), "Democracy in the EU and the role of European Parliament", Roma, Istituto Affari Internazionali, 2009, p. 29 y ss.
} 
de reformas jurídicas coadyuvantes. En este sentido, la principal que ha sido ya acometida, lo que es motivo de optimismo y esperanza, no es otra que la que ha llevado a adoptar, de forma efectiva, la Carta de los Derechos Fundamentales de la Unión Europea. Probablemente, su invocación y aplicación reiterada harán más por la legitimación, la garantía del funcionamiento democrático de la Unión y la consiguiente conformación de una "voluntad general europea", que muchas de las decisiones parciales hasta ahora asumidas ${ }^{30}$.

En este sentido, la incorporación, tras la reforma de Lisboa, de unas destacadas"Disposiciones sobre los principios democráticos", como Título II (arts. 9-12) del reformado Tratado de la Unión Europea, posee, asimismo, a pesar de sus limitaciones, una significación notable ${ }^{31}$. En dicho Título se incluyen referencias apreciables, aunque de carácter más bien complementario, tanto a la democracia participativa ${ }^{32}$, como a la exigencia de transparencia en la acción de los poderes públicos, que no sólo afirman el derecho de todo ciudadano de la Unión a tomar parte en la vida democrática de la misma, insistiendo en que las decisiones que ésta determine se adoptarán de la forma más abierta y próxima posible a los ciudadanos (art. 10.3); o que recalcan la necesidad, ya señalada, de constituir partidos políticos a escala europea, que contribuyan a conformar la conciencia política y a expresar la voluntad de los ciudadanos de la Unión (art. 10.4); sino que establecen, incluso, un mandato efectivo de apertura democrática de las instituciones europeas a los ciudadanos y a sus asociaciones representativas, que supondrá la articulación, a tal fin, de los cauces apropiados para el intercambio público de opiniones en todos los ámbitos de actuación de la Unión (art. 11.1). Ello implica la exigencia de diálogo regular entre ambas partes (art. 11.2); el mandato dirigido, en concreto, a la Comisión, para que mantenga consultas con los interesados (art. 11.3); y la muy destacada determinación de promover la iniciativa legislativa popular (art. 11.4).

Además, dichas disposiciones se vinculan al art. 24 del Tratado de Funcionamiento de la Unión Europea, que, en relación a los principios que sobre "No discriminación y ciudadanía de la Unión" en él se contienen, ordena al Parlamento y al Consejo acordar, por medio de reglamentos, con arreglo al procedimiento legislativo ordinario, los mecanismos y las condiciones que se requieren para la presentación de la "iniciativa ciudadana", conforme a las

\footnotetext{
${ }^{30}$ P. RIDOLA, "La Carta dei Diriiti Fondamentali dell'Unione Europea e lo sviluppo storico del costituzionalismo europeo", en P. RIDOLA, "Diritto comparato e Diritto costituzionale europeo", op. cit., p. 163 y ss.

${ }^{31}$ Cfr., ampliamente, J. Ma PORRAS RAMÍREZ, "La arquitectura institucional de la Unión Europea: consideraciones críticas tras su reforma en el Tratado de Lisboa", en Revista de Estudios Políticos, no 156, 2012, p. 125-166; en especial, p. 134 y ss.

${ }^{32}$ Acerca de la creciente importancia que adquiere la introducción de elementos de democracia participativa y directa en la reformas constitucionales emprendidas en Suiza y en los "Länder" alemanes, abogando por su inclusión en las normas constitutivas de la Unión Europea, vid., P. HÄBERLE, "Europäische Verfassungslehre", op. cit., p. 612 y ss.
} 
previsiones del art. 11.4 TUE ${ }^{33}$. A su vez, dicho precepto reconoce el derecho de petición de todo ciudadano ante el Parlamento Europeo; y a dirigirse al Defensor del Pueblo; junto con el derecho que los ciudadanos de la Unión poseen a ponerse en contacto, por escrito, con cualquiera de las instituciones $\mathrm{u}$ organismos europeos en una de las lenguas oficiales de la Unión y a recibir una contestación en esa misma lengua ${ }^{34}$.

Asimismo, de forma sobresaliente, el Tratado de la Unión Europea determina la posición central que se atribuye a la democracia representativa en su seno ${ }^{35}$. De ese modo, tras proclamar el principio republicano de igualdad, afirmando que las instituciones, órganos y organismos de la Unión proporcionarán un mismo trato a los ciudadanos europeos, que, no obstante, sólo adquirirán su condición de tales si poseen la nacionalidad de un Estado miembro (art. 9); asevera que "El funcionamiento de la Unión se basa en la democracia representativa" (art. 10.1) ${ }^{36}$. De esa proclamación categórica, de acuerdo con la cual se afirma, por un lado, que los ciudadanos están representados en la Unión por el Parlamento Europeo y, por otro, que los Estados miembros lo están en el Consejo Europeo por sus respectivos Jefes de Estado o de Gobierno, y en el Consejo por sus respectivos Gobiernos, se deduce una consecuencia lógica mediatizada por la implícita referencia al principio de legitimación dual de la estructura organizativa de la Unión ${ }^{37}$.

Así, tras afirmar que las principales instituciones políticas de aquélla se considerarán "democráticamente responsables", se precisa, sin embargo, que aquéllas lo serán, ya, directamente, ante los propios ciudadanos europeos, como es el caso del Parlamento europeo, en tanto que representación legítima e inmediata de aquéllos; ya, diferidamente, ante sus parlamentos o ciudadanos nacionales, como en los casos del Consejo Europeo y del Consejo, dada su condición representativa de los gobiernos de los Estados miembros (art. 10.2 y 10.3).

\footnotetext{
33 "Regulation (EU) No. 211/2011 of the European Parliament and of the Council, of 16 February 2011, on the citizens' initiative".

${ }^{34} \mathrm{~A}$. von BOGDANDY entiende que estas medidas, de carácter complementario, son la manifestación de "estrategias para la realización del principio democrático", que tratan de responder a las "mayores restricciones (que afectan) a la materialización del principio de la democracia a través de mecanismos representativos". Cfr., A. von BOGDANDY, "Founding principles", en A. von BOGDANDY and J. BAST (eds.), "Principles of European Constitutional Law", OxfordMünchen, Hart/C.H. Beck, 2010, p. 15-54; en especial, p. 51.

${ }^{35} \mathrm{~J}$. Ma PORRAS RAMÍREZ, "Article 10: the representative democracy», en H. J. BLANKE and S. MANGIAMELI (eds.), "The Treaty on the European Union (TEU). A Commentary", Heidelberg, Springer, 2013, p. 121-154.

${ }^{36}$ A. von BOGDANDY, "A disputed idea becomes law. Remarks on European democracy as a legal principle", en B. KHOLER-KOCH and B. RITTBERGER (eds.), "Debating the democratic legitimacy of the European Union", Lahman, Rowan \& Littlefeld, 2007, p. 33 y ss.

${ }^{37}$ S. MANGIAMELI, "Il ruolo del Parlamento Europeo e il principio della democrazia rappresentativa", en Teoria del Diritto e dello Stato, $\mathrm{n}^{\circ}$ 2, 2008, p. 491 y ss. A. von BOGDANDY, "Founding principles", op. cit., p. 50. A von KOMOROWSKI, "Demokratieprinzip un Europäische Union", Berlin, Duncker \& Humblot, 2010, p. 170 y ss y 1170 y ss.
} 
De acuerdo con esa concepción gradual o "multinivel" de la responsabilidad política, por mucho que se insista, con carácter general, en que la democracia europea habrá de construirse sobre las bases que ofrece el parlamentarismo; al trazar una distinción, reveladora de la persistencia de una doble legitimidad popular o democrática y estatal o internacional, de la Unión, proyectada en sus instituciones políticas ${ }^{38}$, se está entorpeciendo la configuración de un nivel autónomo e integrado de gobierno en el marco de aquélla. Tal hecho se manifiesta fundamentalmente en la remisión a los Estados, en tanto que componentes esenciales de la Unión, del compromiso democrático de velar, a título individual, por que la posición que cada uno de ellos representa y defiende en las reuniones de las instituciones de marcado carácter intergubernamental, como son el Consejo Europeo y el Consejo, sea políticamente fiscalizada a través del procedimiento que cada uno de ellos disponga ante el respectivo Parlamento nacional.

Y es que salta a la vista que semejante visión posee zonas de sombra muy importantes, ya que no considera el sometimiento de las actuaciones conjuntas que desarrollan esas instituciones, que son, por cierto, la auténtica expresión del gobierno político de la Unión, a un efectivo control parlamentario centralizado, susceptible de sustanciarse en el nivel estrictamente comunitario ${ }^{39}$. Tal circunstancia es un signo revelador más de la incompleta proyección del principio democrático en el sistema institucional europeo ${ }^{40}$; hecho éste que se hace más llamativo, si cabe, una vez que se comprueba el esfuerzo realizado por contrarrestar el notable avance que ha supuesto el reforzamiento de la posición del Parlamento Europeo y de los parlamentos nacionales, incorporando, como "fórmula de equilibrio", disposiciones favorecedoras de la posición preeminente otorgada a aquéllas.

En este sentido, cabe destacar, en particular, la sobresaliente ampliación de las competencias atribuidas al Consejo Europeo, institución formalizada

\footnotetext{
${ }^{38}$ Una notable visión de la "democracia compuesta" europea y de sus limitaciones, en J. H. H. WEILER, U. HALTERN, F. C. MAYER, "European democracy and its critique", en West European Politics, Volume 18, Issue 3, 1995, p. 4-39. También, A. von BOGDANDY, "Parlamentarismus in Europa: eine Verfalls- oder Erfolgsgeschichte", en Archiv des Öffentlichen Rechts, 130. Band, Heft 3, 2005, p. 445-464. Y P. KIRCHHOF, "The European Union of States", en A. von BOGDANDY and J. BAST (eds.), "Principles of European Constitutional Law", op. cit., p. 735 y ss. También, A. LÓPEZ CASTILLO, "De la (doble) legitimación de la ConstUE y de su reflejo en la planta institucional de la Unión", en VVAA, "La Constitución Europea. Actas de las X Jornadas de la Asociación de Letrados del Tribunal Constitucional", Madrid, Centro de Estudios Políticos y Constitucionales, 2005, p. 47 y ss; en especial, p. 52.

${ }^{39}$ Debemos plantearnos qué significa la responsabilidad cuando la posición defendida por un ministro de un Estado miembro es rechazada por sus colegas en la correspondiente institución europea. Entonces, como señala V. BOGDANOR, la idea de exigencia de responsabilidad ante los parlamentos nacionales queda debilitada ya que "un ministro no puede ser hecho responsable ante su parlamento nacional de una decisión que tomaron otros". Cfr., V. BOGDANOR, "Legitimacy, Accountability and Democracy in the European Union", London, A Federal Trust Report, 2007, p. 6.

40 D. GRIMM, "Does Europe need a Constitution?", en European Law Journal, no 1, 1995 p. 282-302.
} 
como tal, por vez primera, en Lisboa, tras el fallido intento que supuso, en ese sentido, el Tratado constitucional, al tiempo que se preserva el ejercicio de las mismas, de acuerdo con procedimientos de deliberación y decisión, carentes, casi por completo, de transparencia y control ${ }^{41}$. Esa circunstancia, que actúa en beneficio de los intereses de los gobiernos de los Estados miembros, que trasladan, a menudo, a tales instancias de gobierno la discusión y aprobación de medidas, en ocasiones, impopulares, sorteando las trabas políticas y jurídicas que, en el plano interno, disponen sus propios ordenamientos constitucionales, viene, en cualquier caso, a expresar una práctica política ${ }^{42}$ que, si no se ve compensada con el establecimiento de mecanismos de control efectivos ante el Parlamento Europeo, decantados siquiera sea convencionalmente, supone la ruptura de la "cadena de legitimación democrática" que todo proceso político de toma de decisiones y de consiguiente exigencia de responsabilidad política ha de observar ${ }^{43}$.

Constituye así un hecho cierto que los principios que enuncia el Título II del Tratado de la Unión Europea no se extienden plenamente a todas las instituciones y a las relaciones que entre las mismas se establecen, conformando su sistema de gobierno. No en vano, éste alberga a algunas, de la mayor relevancia, dado el carácter promocional de la integración económica y monetaria al que orientan, respectivamente, sus actuaciones, que no parecen verse afectadas, si no de forma muy parcial, por los mismos, como sucede con la Comisión o el Banco Central Europeo, instituciones a las que se unen otros órganos y organismos de segundo nivel, considerados, también, dado su sesgo tecnocrático, agencias independientes. Sin duda, esta disconformidad en modo alguno se ajusta a las exigencias democráticas que resultan inherentes al proceso de integración política ${ }^{44}$.

De ahí que todo ello nos lleve a afirmar que, en la actualidad, la Unión mantiene, entremezclados, rasgos propios de una organización internacional y de un Estado federal, o, más bien, una vez constatado quién domina en la misma el proceso decisorio, propiamente, rasgos federales, asociados a la democracia parlamentaria, insertos en los moldes, en parte incólumes, de una organización internacional. La Unión se muestra así, en palabras de J. H. H. Weiler, como una confederación en el plano político, dada la preeminencia otorgada a los Estados en su seno, y como una federación en el jurídico, habida cuenta de la significación otorgada al principio de la primacía del

\footnotetext{
${ }^{41}$ Así, notablemente, F. MANCINI, "Europe: the case for statehood", en European Law Journal, vol. 4, no 1, 1998, p. 29-42; en especial, p. 39-40.

42 D. N. CHRYSSOCHOOU, "EU Democracy and the democratic deficit", en C. CINI (ed.), "European Union Politics", Oxford, Oxford University Press, 2003, p. 366 y ss.

${ }^{43}$ C. HARLOW, "Accountability in the European Union", Oxford, Oxford University Press, 2002, p. 168 y ss. También, A. FOLLESDAL and A. HIX, "Why there is a democratic deficit in the EU? a response to Majone and Moravcsik", en Journal of Common Market Studies, 2006, 44 (3), p. $533-562$.

${ }^{44} \mathrm{~S}$. BREDT, "Prospects and limits of democratic governance in the EU", en European Law Journal, vol. 17, no 1, 2001, p. 35-65; en especial, p. 37.
} 
Derecho europeo, a los efectos de garantizar, en su ámbito propio de actuación, la aplicación preferente de las normas por aquélla elaboradas ${ }^{45}$. Esto explica, a fin de describirla, la tendencia creciente a hablar de la existencia de un "intertwined government" ${ }^{\text {", }}$, más y mejor que de un "multilevel government" ${ }^{47}$, de una forma de gobierno entrelazada o mixta, de naturaleza confederal, que gira en torno a la interdependencia constante de la Unión y los Estados miembros, a modo de compromiso pretendidamente duradero.

Así, la Unión se muestra, cuando menos a día de hoy, como una organización jurídico-política compuesta, en proceso paulatino de conformación, que aspira a ser complementaria, que no alternativa o sustitutiva, de las comunidades políticas estatales existentes ${ }^{48}$, a las que se superpone en aquellos sectores, cada vez más numerosos y relevantes, objeto de su competencia. En este sentido, la propia atribución de la condición de ciudadano de la Unión a quien ostente previamente la de nacional de un Estado miembro (art. 20 TFUE), resulta muy reveladora, al influir decisivamente en la legitimación del poder político que ejerce la Unión por medio de sus instituciones. No en vano, dicha opción revela la decisión consciente de los Tratados de seguir concibiendo al cuerpo político supraestatal, no como a un ente unitario y homogéneo, sino, más bien, como al agregado resultante de las aportaciones provenientes de los diferentes pueblos de Europa, fundadas en sus respectivas identidades nacionales ${ }^{49}$. Así, generalizando la criticable argumentación expresada por diferentes tribunales constitucionales, el límite a la atribución de competencias a la Unión por parte de los Estados miembros aparece constituido por los elementos o factores determinantes de la "identidad constitucional" de dichos Estados miembros ${ }^{50}$.

\footnotetext{
${ }^{45}$ Señala así que su ordenación institucional es confederal, mientras que su conformación jurídica es federal. Cfr., J. H. H. WEILER, "The transformation of Europe" (1991) (Trad. esp., en "Europa, fin de siglo", Madrid, Centro de Estudios Constitucionales, 1995, p. 13-126; en especial, p. 111). Más extensamente, reitera esta idea en su trabajo "In the defence of the status quo: Europe's constitutional sonderweg", en J. H. H. WEILER and M. WIND (eds.), "European constitutionalism beyond the State", op. cit., p. 18 y ss.

${ }_{46} \mathrm{P}$. KIRCHHOF, "The balance of powers between national and European institutions", en European Law Journal, vol. 5, nº 3, 1999, p. 225-242; en especial, p. 230-232; y, más recientemente, vid., J. ZILLER, «Separation of powers in the European Union's intertwined system of government", en II Politico, $n^{0} 3,2008$, p. 133-179; en especial, p. 167 y ss.

47 En expresión ya clásica de I. PERNICE, "Multilevel constitutionalism and the Treaty of Amsterdam: European constitution-making revisited", en Common Market Law Review, $\mathrm{n}^{\circ} 36$, 1999, p. 703 y ss.; y, también, I. PERNICE, "The Treaty of Lisbon: multilevel constitutionalism in action", en Columbia Journal of European Law, n 15 , vol. 3, 2009, p. 25 y ss.

${ }^{48}$ P. KIRCHHOF, "The European Union of States", en A. von BOGDANDY and J. BAST (eds.), "Principles of European Constitutional Law", op. cit., p. 743.

${ }^{49}$ L. Ma DíEZ-PICAZO GIMÉNEZ, «La naturaleza de la Unión Europea”, op. cit., p. 102-103.

${ }^{50}$ Vid. Tribunal Constitucional Federal alemán 2BvR 2134, 2159/92 (Resolución de 12 de octubre de 1993: Tratado de Maastricht); y 2BvE 2/08, 30/06/09 (Resolución de 30 de junio de 2009: Tratado de Lisboa); Consejo Constitucional francés, Decisión № 2007-560 DC (Resolución de 20 de diciembre de 2007: Tratado de Lisboa); Tribunal constitucional polaco, Decisión Ref. No. K 32/09 (Resolución de 24 de noviembre de 2010: Tratado de Lisboa). Cfr., al respecto, F. VECCHIO,
} 
Con tales presupuestos se explica por qué la Unión se ha dotado de una articulación institucional, constitutiva de un modelo único e inclasificable, particularmente complejo y ambiguo, que responde, de forma en buena medida contradictoria, pese a su analogía con la génesis histórica de ciertos ordenamientos federales ${ }^{51}$, a la voluntad, hasta ahora, conjunta, de, inicialmente, asociar a los Estados y, posteriormente, de integrar a los pueblos de Europa.

\section{LOS EFECTOS CONSTITUCIONALES DE LA CRISIS ECONÓMICA Y FINANCIERA}

Sin embargo, la grave crisis económica y financiera que, en la actualidad, sufre el continente europeo, la cual obliga a la mayoría de los Estados de la Unión a alcanzar una mayor coordinación de sus políticas económicas, otorgando a la unión monetaria el necesario respaldo de los mecanismos propios de una unión económica, bancaria y fiscal, si bien ha superado la resistencia inicial de algunos a avanzar, siquiera lentamente, en pos de la consecución de un auténtico gobierno económico unificado, lo ha hecho a costa de generar un nuevo déficit de legitimidad democrática ${ }^{52}$. No en vano, dicho gobierno descansa en un esquema de funcionamiento intergubernamental, al tiempo que discurre fuera, esencialmente, del marco normativo común establecido en los Tratados constitutivos de la Unión Europea. Así, se observa al analizar los distintos y sucesivos instrumentos de asistencia financiera aprobados desde que estalló la crisis, mediante los cuales se ha tratado de dar respuesta a las necesidades sobrevenidas, sin partir de un plan preconcebido $^{53}$. Dichos instrumentos son, esencialmente, el Acuerdo de Préstamo a Grecia, de 2010, el Mecanismo Europeo de Estabilización Financiera ("European Financial Stabilisation Mechanism"), también de 2010, y el Mecanismo Europeo de Estabilidad ("European Stability Mechanism"), de $2012^{54}$. Un sucinto análisis de los mismos revela las transformaciones constitucionales que, en los últimos años, ha experimentado, la Unión.

\footnotetext{
"Primacía del Derecho Europeo y contralímites como técnicas para la relación entre ordenamientos", en Revista de Derecho Constitucional Europeo, n 17, 2012.

${ }^{51}$ C. J. FRIEDRICH, "Constitutional Government and Democracy". (Trad. Esp., Madrid, Instituto de Estudios Políticos, 1968, p. 24 y ss.) y M. BURGESS, "Federalism and European Union. The Building of Europe", New York/London, Routledge, 2000, p. 55 y ss.

${ }_{52}$ Inicialmente, vid., con carácter general, J. H. H. WEILER, "The European Union belongs to its citizens: three immodest proposals", en European Law Review, 1997, 22 (2), p. 150 y ss.; también, V. BOGDANOR, "Legitimacy, Accountability and Democracy in the European Union", op. cit., p. 6. Y, destacadamente, en relación a la situación de crisis actual, cfr., F. BALAGUER CALLEJÓN, "Crisis económica y crisis constitucional en Europa", en Revista Española de Derecho Constitucional, $\mathrm{n}^{\circ}$ 98, 2013, p. 91-107.

${ }^{53}$ A. DE GREGORIO MERINO, "Legal developments in the Economic and Monetary Union during the Debt Crisis: the Mechanisms of Financial Assistance", en Common Market Law Review, $\mathrm{n}^{\circ} 49$, 2012, p. 1615 y ss.

${ }^{54}$ Cfr., un detenido análisis de los mismos en A. J. MENÉNDEZ, "La Mutación Constitucional de la Unión Europea", en Revista Española de Derecho Constitucional, nº 96, 2012, p. 41-98; en especial, p. 54 y ss.
} 
Así, en primer lugar, en referencia al Acuerdo de Préstamo a Grecia, ha de apreciarse que el mismo se plasma en un acuerdo bilateral de préstamo, suscrito conforme a las reglas del Derecho internacional, por el Estado receptor, en este caso, Grecia, y los demás Estados Miembros de la Eurozona, conjuntamente con el Fondo Monetario Internacional, de conformidad con ciertas condiciones particularmente rigurosas, expresadas en el llamado "Memorando de Entendimiento" ("Memorandum of Understanding") (MoU). Dichas condiciones implican, esencialmente, la exigencia al Estado prestatario de que proceda a la reducción de su déficit presupuestario, y a que refuerce y profundice la vigilancia fiscal, introduciendo reformas, de extraordinaria envergadura, en múltiples ámbitos. Tales requisitos están orientados a lograr la adecuación del préstamo concedido a los objetivos marcados genéricamente por el Derecho de la Unión. La supervisión de su cumplimiento se hizo corresponder a la Comisión Europea, al Banco Central Europeo y al Fondo Monetario Internacional.

En segundo lugar, ha de aludirse al Mecanismo Europeo de Estabilización Financiera (EFSM), aprobado tras comprobar la extensión de la crisis financiera a otros Estados de la Eurozona, esto es, a Irlanda y Portugal, nuevamente a Grecia, a Chipre y, finalmente, hasta el presente, a España. Se trata de un mecanismo temporal que, si bien apela a lo estipulado en el art. 122.2 TFUE, que prevé la ayuda financiera extraordinaria a un Estado Miembro en el caso de que "catástrofes naturales o acontecimientos excepcionales" que dicho Estado "no pudiere controlar", causen dificultades graves o el riesgo de que se produzcan, conlleva, asimismo, la creación del Fondo Europeo de Estabilidad Financiera, en orden a alcanzar una mayor eficiencia en la asistencia. El mismo se provee a través de una corporación o sociedad, instituida únicamente por los miembros del Eurogrupo, que actuando al margen del Derecho de la Unión, se dispone a la concesión de préstamos, sujetos a una severa condicionalidad, a aquellos Estados Miembros de la Zona Euro que lo precisen y requieran, "en aras de preservar la sostenibilidad de sus finanzas públicas" y de "restaurar su capacidad de autofinanciación en los mercados financieros" ${ }^{\prime 55}$. Nuevamente, en estos casos, la Comisión Europea y el Banco Central Europeo se reservan la negociación, supervisión y ejecución de los programas de ayuda a través de la llamada "troika".

Finalmente, ante la gravedad y extensión alcanzada por la crisis, el Mecanismo Europeo de Estabilidad (ESM), constituye un instrumento, en este caso permanente, diseñado para atender las necesidades financieras extraordinarias que sobrevengan a los Estados Miembros de la Eurozona. Dicho Mecanismo ha sido creado, mediante la firma de un tratado internacional, por los diecisiete miembros pertenecientes a aquélla. El mismo ha conllevado, por iniciativa de Alemania, su convalidación en el nuevo párrafo incluido en el

\footnotetext{
${ }^{55}$ Reglamento $n^{\circ} 407 / 2010$.
} 
vigente art. 136 TFUE, que viene así a contemplarlo. No obstante la cobertura indicada, el Mecanismo posee una naturaleza estrictamente intergubernamental, al desenvolverse su articulación y funcionamiento fuera del marco normativo de los Tratados constitutivos de la Unión. No en vano, el mismo ha dado lugar a la creación de una institución financiera internacional, orientada a movilizar fondos y a proveer un soporte financiero estable, conforme a una estricta condicionalidad, que conlleva la adopción de programas de ajuste macroeconómico y otros requisitos preestablecidos, garantes de la observancia de una rigurosa disciplina presupuestaria, a los firmantes de dicho acuerdo que sufran o estén amenazados de sufrir problemas financieros que pongan en riesgo la estabilidad del conjunto de la Zona Euro.

Es obvio que la creación de estos instrumentos para la gestión de la asistencia financiera al margen del marco normativo de los Tratados constitutivos de la Unión Europea persigue soslayar las limitaciones y garantías que establece el Derecho de la Unión. Así, recurriendo alternativamente al Derecho internacional, esto es, reforzando la cooperación intergubernamental, se otorga a los Estados Miembros una mayor flexibilidad, o, lo que es igual, la posibilidad de actuar con una mayor libertad, al no requerirse su sometimiento a las restricciones y controles habituales, en aras de alcanzar una mayor eficacia. En concreto, el Tratado que establece el Mecanismo Europeo de Estabilidad (ESM)) simplifica y agiliza el procedimiento de toma de decisiones, beneficiando a los Estados Miembros más poderosos, esto es, a aquellos que contribuyen al mismo aportando mayores fondos, criterio éste disconforme con los Tratados constitutivos de la Unión, los cuales establecen, a modo de garantía democrática, un delicado sistema de equilibrios para evitar una situación claramente perjudicial para los Estados pequeños. De este modo, sorteando las disposiciones del Tratado de la Unión Europea (TEU) y del Tratado de Funcionamiento de la Unión Europea (TFUE), ciertamente inadecuadas e insuficientes para afrontar la actual situación de crisis financiera, se margina, de forma consciente el "método comunitario" o supranacional de toma de decisiones ${ }^{56} \mathrm{y}$, en particular, a su institución más representativa, el Parlamento Europeo, la cual se ve así condenada al desarrollo de una función claramente subalterna.

Con ello, la nueva cesión de soberanía efectuada por parte de los Estados pertenecientes a la Eurozona, en aras de alcanzar ese ansiado gobierno económico unificado, no se ve acompañada de un progreso en la construcción de un esquema organizativo sustentado cívicamente en el marco del proceso político, voluntario y consciente, de integración democrática supranacional. Más bien se opta por la creación de una estructura institucional de naturaleza intergubernamental, al servicio del desarrollo de esa nueva gobernanza

\footnotetext{
${ }^{56}$ S. PEERS, "Towards a new form of EU Law? The use of EU Institutions outside the EU legal framework", en European Constitutional Law Review, no 9 (1), 2013, p. 37-72; en especial, p. 7 y ss.
} 
económica, que consagra la desigualdad entre los Estados Miembros ${ }^{57}$. Así, la atribución al Consejo Europeo de la Eurozona, esto es, a la reunión de los Jefes de Estado y de Gobierno de los Estados Miembros pertenecientes a la Zona Euro (actualmente diecisiete, de un total de veintiocho Estados Miembros de la Unión), a la Comisión Europea (y, en su seno, al Comisario de Asuntos Económicos y Monetarios) y al Banco Central Europeo, del control de los mecanismos de asistencia y los poderes de supervisión, evaluación y sanción, destinados a exigir el cumplimiento de los objetivos de estabilidad financiera, definidos normativamente en el Pacto de Estabilidad Crecimiento, y dispuestos, en ayuda de aquellos Estados Miembros actualmente sometidos a graves dificultades, si bien permite la adopción de decisiones urgentes con mayor facilidad y flexibilidad, aunque de un modo que el Derecho de la Unión consideraría inaceptable, generan, al tiempo, una importante fragmentación de la Unión. No en vano, las mismas ponen en peligro el proceso, hasta ahora conjunto, de integración europea, el cual se ve obligado a discurrir a diferentes velocidades en función de la pertenencia, o no, de sus Estados miembros, a la Zona Euro; al tiempo que subvierte los fundamentos mismos del ordenamiento jurídico europeo, alterando las reglas comunes de juego y sus garantías democráticas inherentes.

Ciertamente, una Unión Europea compuesta por veintiocho Estados, cuya voluntad de integración y acuerdo es muy diferente, proporciona problemas evidentes de funcionamiento conjunto. Así, aun siendo cierto que existen ámbitos importantes en los que concurren todos los Estados Miembros de la Unión, hallándose obligados a cooperar solidariamente entre sí, como en las cuestiones que afectan al mercado único, lo cierto es que hallamos, también, otros en los que, con el transcurso del tiempo, y, de forma creciente, sobre todo a partir de los años noventa del pasado siglo (Tratado de Maastricht de 1992), se ha hecho evidente la diferente voluntad de participación de los Estados en los mismos. De ese modo, cuando el Tratado de Ámsterdam introdujo, en 1996, la cláusula de cooperación reforzada, contemplada en el vigente art. 20 del Tratado de la Unión Europea (versión Lisboa), no vino sino a reconocer y canalizar esa posibilidad. $Y$ ha sido, precisamente, el proceso de integración económica, emprendido por los Estados Miembros de la Zona Euro, lo que ha evidenciado, en mayor medida, las divergencias existentes entre los Estados de la Unión, al generar una división entre los diecisiete dispuestos a alcanzar en este campo "una unión cada vez estrecha", avanzando más rápidamente en la consecución de la misma, y, por otra parte, los once restantes, que no se muestran, hasta el presente, proclives a ello ${ }^{58}$. Para disimular esta realidad, el Tratado que establece el Mecanismo Europeo de Estabilidad (ESM) se cuida de indicar

\footnotetext{
${ }^{57}$ A. J. MENÉNDEZ, "La Mutación Constitucional de la Unión Europea", op. cit. p. 78-83.

${ }^{58}$ Editorial Comments, "Some Thoughts Concerning the Draft Treaty on a Reinforced Economic Union", en Common Market Law Review, n 49, 2012, p. 11 y ss.
} 
que su regulación, creada estrictamente para afrontar la crisis financiera de determinados Estados Miembros, ni pretende excepcionar la aplicación del Derecho de la Unión, ni conducir a una marginación de los Estados ajenos a la Eurozona, cuya participación no impide. Sin embargo, la práctica se encarga cotidianamente de desmentir esta afirmación.

Y es que, ciertamente, el Tratado que establece el Mecanismo Europeo de Estabilidad (ESM), en tanto que instrumento permanente, y más importante diseñado hasta la fecha, para la gestión de la crisis financiera de la Eurozona, ha efectuado un intenso apoderamiento de las instituciones europeas de más dudosa independencia y transparencia, y carácter menos representativo, al contar con una más débil e indirecta legitimación democrática, esto es, particularmente, la Comisión Europea y del Banco Central Europeo, situándolas, a un tiempo, al margen del marco normativo de los Tratados constitutivos. No obstante, como ha puesto de manifiesto del Tribunal de Justicia de la Unión, ello no puede significar su completa desvinculación del mismo, dado que su naturaleza no puede verse, por completo, alterada, haciendo caso omiso de las restricciones orgánico-funcionales que el Derecho originario de la Unión establece, por ser quién, al fin y al cabo, las ha creado, haciendo de él derivar su existencia ${ }^{59}$.

En todo caso, y a un haciendo estas salvedades, el ESM refuerza extraordinariamente las competencias de estas Instituciones. Así, determina que será la Comisión Europea quien tramite las solicitudes de ayuda financiera de los Estados Miembros a la Junta de Gobernadores del ESM, cuyo presidente confiará a la Comisión determinadas tareas en relación con el Banco Central Europeo, como la valoración de los riesgos de estabilidad para la Zona Euro, los cuales serán, también, objeto del análisis del Banco; que valorará, además, la sostenibilidad del déficit público, conjuntamente con el Fondo Monetario Internacional; al tiempo que las necesidades financieras, actuales y potenciales del Estado Miembro afectado (art. 13 del Tratado ESM). De todos modos, la decisión final acerca de la concesión de la ayuda al Estado solicitante corresponderá a la Junta de Gobernadores, que, en caso de concederse, encomendará a la Comisión Europea, al Banco Central Europeo, y, a ser posible, al Fondo Monetario Internacional, el cometido de negociar con el Estado Miembro el Memorando de Entendimiento (MoU) que establece las condiciones de concesión de la asistencia financiera en cuestión. Dicho Memorando será firmado por la Comisión Europea, tras su aprobación por la Junta de Gobernadores, velando por que el mismo se muestre, en garantía del interés general, conforme con el Derecho de la Unión $^{60}$. Seguidamente se determina que la Comisión Europea, junto con el Banco Central Europeo y, a ser posible, con el Fondo Monetario Internacional,

\footnotetext{
${ }^{59}$ En este sentido, cfr., S. PEERS, "Towards a new form of EU Law...", op. cit., p. 8 y ss.

${ }^{60}$ Asunto C-370/12, Pringle vs. The Government of Ireland, Ireland and the Attorney General (2012), párrafo 164.
} 
habrá de controlar el cumplimiento de las condiciones anexas a la ayuda financiera concedida al Estado Miembro. Tales poderes conferidos a la Comisión, en relación con el Mecanismo de Estabilidad Financiera, fueron atribuidos a la misma por los, entonces, veintisiete Estados de la Unión, a través de una decisión intergubernamental ${ }^{61}$. No obstante, el papel reservado, a modo de contrapartida, al Tribunal de Justicia de la Unión no debe ser menospreciado, ya que se habilita al mismo para intervenir en el caso de que un Estado Miembro del ESM impugne alguna decisión de la Junta de Gobernadores, en relación a alguna disputa abierta entre el mismo y los contenidos del propio Tratado, o con otro u otros Estados Miembros, en relación con la interpretación y aplicación del Tratado, incluyendo las que afectan a la compatibilidad de las decisiones adoptadas y el Tratado (art. 37.3 TESM).

Lo expuesto se inscribe en el marco del acuerdo pactado, el 9 de diciembre de 2011, por los Jefes de Estado o de Gobierno de los Estados miembros de la Zona Euro, en el que se determinó el establecimiento de una "arquitectura reforzada para la unión económica y monetaria", a fin de facilitar, tanto la aplicación de las medidas que contempla el Tratado de Funcionamiento de la Unión Europea en la materia (arts. 121, 126 y 136), como el desarrollo de las propuestas legislativas presentadas por la Comisión Europea para reforzar la supervisión económica y presupuestaria de aquellos Estados miembros que padecen o corren el riesgo de padecer dificultades graves en lo que respecta a su estabilidad financiera. De ese modo, se perseguía la ejecución sin demoras del llamado Pacto de Estabilidad y Crecimiento revisado ${ }^{62}$, que ha supuesto la introducción, de forma vinculante para los Estados Miembros de la Zona Euro, de la "regla de equilibrio presupuestario", sujeta a la jurisdicción del Tribunal de Justicia de la Unión Europea (art. 273 TFUE), y, en caso de incumplimiento, la previsión de la posible imposición de sanciones coercitivas, en el marco del procedimiento de déficit excesivo de la Unión Europea, a aquellos Estados que se separen o contradigan los objetivos acordados.

Así, alegando el propósito de emplear, de forma más activa e intensa, la cooperación reforzada entre dichos Estados (art. 20 TUE), en aras de alcanzar una mejora de la gobernanza económica de la Zona Euro, veinticinco de ellos, han acordado la adopción del Tratado de Estabilidad, Coordinación y Gobernanza de la Unión Económica y Monetaria, en diciembre de $2012^{63}$. El mismo ha confirmado, en relación a esta materia, en palabras de F. Balaguer, "la traslación de las decisiones a un espacio europeo sin ciudadanía". No en vano, con el pretexto de la crisis y conforme a lo dispuesto en dicho Tratado,

\footnotetext{
${ }^{61}$ Documento del Consejo no $11758 / 11$.

${ }^{62}$ Cfr., Reglamento (EC) $n^{\circ}$ 1466/97, del Consejo, de 7 de julio de 1997, modificado por el Reglamento (UE) $n^{\circ}$ 1175/2011, del Parlamento Europeo y del Consejo, de 16 de noviembre de 2011.

${ }^{63}$ Con carácter general, cfr., P. CRAIG, "The Stability, Coordination and Governance Treaty: principle, politics and pragmatism", en European Law Review, no 37 (3), p. 231-248.
} 
los Jefes de Estado o de Gobierno de las Partes Contratantes cuya moneda es el euro, junto con el Presidente de la Comisión Europea (art. 12), prescindiendo del método de funcionamiento habitual, propio de la Unión, han asumido el cometido de imponer, supervisar y evaluar la aprobación y ejecución de programas y planes de obligatorio cumplimiento por parte de los Estados, que implican, además de la exigencia de adopción de iniciativas estructurales de reforma económica (en materia laboral, fiscal, de pensiones, energética, bancaria...), la autorización y validación de los planes presupuestarios anuales y de las emisiones de deuda pública de los Estados, junto con la aplicación de un mecanismo automático de medidas correctoras y sancionadoras.

Tales mandatos han llegado hasta el extremo de imponer, de manera urgente, la reforma de las Constituciones de los Estados de la Zona Euro sometidos a graves tensiones financieras, a fin de obligar a los mismos a garantizar, en particular, en lo que toca a la transposición de la llamada "regla de equilibrio presupuestario", la satisfacción de los compromisos adquiridos. $Y$ todo ello, sin dar lugar, dado su carácter vinculante, a que una medida de semejante trascendencia deje margen alguno a debate o discusión, en el ámbito estatal respectivo ${ }^{64}$.

Todas estas iniciativas, fundadas en el Pacto de Estabilidad y Crecimiento, y desarrolladas al amparo de la crisis, no han hecho sino profundizar en el déficit democrático de la Unión, desapoderando de competencias a los Estados, a través de procedimientos que se caracterizan por su escasa transparencia e informalidad, además de por su falta de control. Como se ha indicado, mediante los mismos se adoptan decisiones de la mayor importancia, que afectan a la vida cotidiana de las personas, más sin su concurso o participación. Ello revela cómo los "déficits de legitimidad" de la Unión Europea, esto es, de la construcción del primer proyecto mundial consistente de democracia pos estatal, siguen no sólo presentes, sino agudizados con ocasión de la actual crisis, no permitiendo a la misma cumplir con el propósito tendencial que aspira a que el proceso de integración europea se sustente, plenamente, en la voluntad de los ciudadanos, promoviendo su participación política activa, directamente o a través de las instituciones ${ }^{65}$.

De ese modo, la pérdida de confianza ciudadana que hoy se advierte, de manera creciente, lo es así, no sólo en el proyecto europeo, sino también en una democracia que se considera amputada, al haberse construido al margen de la propia ciudadanía, que observa la debilidad del "demos europeus", al tiempo que la desustancialización del "demos" nacional-estatal, o, lo que es igual, que es consciente de cómo el pueblo ha perdido capacidad de decisión

\footnotetext{
${ }^{64}$ Acerca de la afectación contemporánea del nivel constituyente de los Estados y de la democracia pluralista misma, cfr., F., BALAGUER CALLEJÓN, "Crisis económica y crisis constitucional en Europa", op. cit., p. 102 y ss.

${ }^{65}$ J. HABERMAS, "Zur Verfassung Europas. Ein Essay". (2012). (Trad. esp., Madrid, Trotta, 2012, p. 39 y ss.)
} 
en el ámbito interno, a la vez que su voluntad es ignorada o sigue sin ser tenida en consideración en Europa.

Por eso, teniendo en cuenta el gran tamaño que la Unión ha alcanzado y la diferente voluntad política observada entre sus miembros a la hora de avanzar en los procesos de integración, quizá convenga acoger la propuesta que promueve una reforma profunda de la arquitectura institucional existente, a fin de que una Unión Europea renovada, fiel a sus valores y objetivos, en el contexto de un mundo globalizado, se convierta, realmente, en un espacio de convergencia política, económica y social, capaz de dar respuesta legítima y eficaz a las expectativas y demandas de sus ciudadanos. Quiere con esto decirse que Europa necesita, más que nunca, de una constitución, que otorgue legitimidad a sus instituciones, elegidas efectivamente por sus ciudadanos, delimitando sus competencias, sujetas a un efectivo control. Ello resulta de la convicción de que los déficits y lagunas que, en la actualidad, manifiesta el gobierno económico de la Unión Europea no son sino el reflejo de la carencia de una verdadera unión política. Por eso, se hace necesario abrir un proceso constituyente, articulado por medio de una convención, en la que estén representados el Parlamento europeo y los parlamentos nacionales, los gobiernos, el Comité de las Regiones y el Comité Económico y Social. El mismo deberá posibilitar un amplio debate en los medios de comunicación europeos, a fin de alentar la participación de una sociedad civil que ha de estar llamada, finalmente, a ratificarlo, por medio de un referendo del conjunto de los ciudadanos europeos, no organizado, por tanto, de país a país. Únicamente así podrá hacerse efectivo un auténtico y definitivo salto adelante democrático.

La iniciación de este proceso constituyente debería ser el tema central de las próximas elecciones europeas de 2014, a fin de que el mismo sirva para otorgarle al proyecto europeo la legitimidad y la credibilidad de la que hoy carece, y que se le exige, a fin de convertirlo en respuesta ejemplar, por parte de Europa, a los desafíos crecientes, aún no adecuadamente atendidos, de un mundo globalizado. 